\title{
THE EFFECT OF DRUGS IN THE PRODUCTION OF AGRANULOCYTOSIS WITH PARTICULAR REFERENCE TO AMIDOPYRINE HYPERSENSITIVITY ${ }^{1}$
}

\author{
By WILLIAM DAMESHEK AND ABRAHAM COLMES \\ (From the Medical Clinic and Pathology Department, Beth Israel Hospital, Boston)
}

(Received for publication September 19, 1935)

Sufficient evidence has accumulated in the last two years to indicate the importance of various drugs as etiological agents in the development of agranulocytosis. Although multiple factors are probably operative in a given case, it is apparent that the administration of a drug, usually amidopyrine, has frequently been the determining factor. First to suggest the possibility that certain drugs, particularly those containing a benzol ring, might be etiological agents was Kracke (1). Madison and Squier (2) presented the first cleancut clinical evidence indicating the relationship of a drug, usually amidopyrine, to the disease. These observations were followed by numerous clinical reports, all of them incriminating such drugs as amidopyrine given either singly or in combination with barbiturates (allonal, peralga, etc.), phenacetin, arsphenamine, neo-arsphenamine, and dinitrophenol. Many of these reports were inconclusive, definite evidence for the drugdisease relationship being very scanty. Reznikoff (3), and more recently Jackson and Parker (4) examined the evidence for this relationship, and concluded that certain drugs undoubtedly played an important part in the causation of the disease, although the exact mechanism was unknown. Madison and Squier (2), Benjamin and Biederman (5), Sturgis and Isaacs (6), Rawls (7), Zinberg, Katzenstein, and Wise (8) and others were able to produce varying degrees of granulocytopenia by the administration of amidopyrine to patients who had recovered from the disease. All of these authors speculated regarding the mechanism of the ensuing granulocytopenia, and most of them concluded that some form of hypersensitivity to the drug was present.

The present communication deals with the study of a group of four patients who recovered from the disease. In all of them a history of the use of amidopyrine prior to onset of

1 This is the fifth of a group of studies on agranulocytosis. the disorder was present. In two of these individuals the administration of amidopyrine by mouth resulted in reproduction of the original disease in all its clinical and hematological characteristics. Skin tests with amidopyrine by the scratch method were negative in all four cases. The intradermal injection, however, of a mixture of blood serum and a solution of amidopyrine in three patients resulted in strikingly positive reactions, and in two instances was followed by the development of the disease in all its hematological and clinical aspects. The results obtained in the study of these four cases are the subject of the present report.

\section{MATERIALS AND METHODS}

The four patients selected for special study were part of a larger group of twelve cases of agranulocytosis in which the history relating to the use of drugs had been definitely ascertained. The various possible etiological factors in these cases have been tabulated (Table I). The drug factor appears to be especially important because it was present in each case and was the only constant one among the many diverse elements present. Amidopyrine had been used prior to the disease in six cases; amidopyrine in combination with a sedative in the form of "allonal" in two other cases. In two cases dinitrophenol had been administered; and in one case "pantopon" in large dosage had been given postoperatively. Most of the patients had suffered from some chronic disease, and in two instances there was definite evidence of previous involvement of the bone marrow (pernicious anemia in Case 6; hypoplastic anemia following the use of Fowler's solution in Case 11). In addition, various exciting causes such as acute infections were frequently present, together with other questionable elements as alcoholism, inadequate diet, etc. Each case probably represented a diversity of etiological factors, the only constant one being that of a drug, usually amidopyrine. 
TABLE I

Possible etiological factors in a consecutive series of cases of agranulocytosis

\begin{tabular}{|c|c|c|c|c|c|c|c|}
\hline $\begin{array}{c}\text { Case } \\
\text { number }\end{array}$ & Age & Sex & Drug & Acute disease & Chronic disease & Other factors & $\begin{array}{l}\text { End } \\
\text { result }\end{array}$ \\
\hline 1 & $\begin{array}{c}\text { years } \\
49\end{array}$ & $\mathbf{M}$ & Arsphenamine & $\begin{array}{l}\text { Secondary syphilis, } \\
\text { pneumococcus } \\
\text { pneumonia }\end{array}$ & $\begin{array}{l}\text { Diabetes, hyperten- } \\
\text { sion }\end{array}$ & & Death \\
\hline 2 & 49 & $\mathbf{F}$ & Amidopyrine & Cold, sinusitis & Asthma, sinusitis & ?Allergy & Recovery \\
\hline 3 & 45 & F & Amidopyrine & $\begin{array}{l}\text { Infections of throat, } \\
\text { fingers, toe }\end{array}$ & Migraine & $\begin{array}{l}\text { Cycles of granulocyto- } \\
\text { penia; oophorectomy } \\
\text { and hysterectomy }\end{array}$ & Recovery \\
\hline 4 & 47 & $\mathbf{M}$ & $\begin{array}{l}\text { Amidopyrine } \\
\text { and sedatives }\end{array}$ & $\begin{array}{l}\text { Extraction of tooth. } \\
\text { Maxillary sinusi- } \\
\text { tus }\end{array}$ & & & Recovery \\
\hline 5 & 27 & F & Amidopyrine & Rheumatic fever & $\begin{array}{l}\text { Rheumatic heart } \\
\text { disease }\end{array}$ & Hemi-thyroidectomy & Recovery \\
\hline 6 & 42 & F & Amidopyrine & Abscessed teeth & Pernicious anemia & Alcoholism; debility & Recovery \\
\hline 7 & 46 & F & Dinitrophenol & & Obesity & Inadequate diet & Death \\
\hline 8 & 33 & F & Pantopon & $\begin{array}{l}\text { Operation, acute } \\
\text { salpingitis }\end{array}$ & $\begin{array}{c}\text { Chronic pelvic } \\
\text { inflammation }\end{array}$ & $\begin{array}{l}\text { Vomiting; } \\
\text { ?peritonitis }\end{array}$ & Recovery \\
\hline 9 & 43 & F & $\begin{array}{l}\text { Amidopyrine, } \\
\text { allonal }\end{array}$ & & Anal infection & & Recovery \\
\hline 10 & 40 & F & Dinitrophenol & & Obesity & Inadequate diet & Recovery \\
\hline 11 & 50 & F & Allonal & External otitis & $\begin{array}{l}\text { Psoriasis, hypoplas- } \\
\text { tic anemia }\end{array}$ & & Death \\
\hline 12 & 58 & $\mathbf{M}$ & Amidopyrine & Headache & & ?Allergy & Death \\
\hline
\end{tabular}

Eight of the twelve cases recovered after vigorous therapy with certain of the nucleic acid derivatives, either a mixture of the pentose nucleotides ("pentnucleotide") or the more simple adenine sulphate being used.

Several methods of study were utilized in the four selected cases: (1) Amidopyrine was administered orally in dosage of 5 to 50 grains daily. (2) Scratch tests were made on the forearm with a 5 per cent solution of amidopyrine in distilled water. (3) Patch tests were made by applying a paste of moistened amidopyrine to the forearm, the results being noted at the expiration of 24 hours. (4) In two cases, a small amount of the subject's serum was injected intradermally into a normal person's forearm simultaneously with a solution of amidopyrine. (5) Intradermal tests with a 5 per cent solution of amidopyrine in distilled water were made, about 0.02 to $0.03 \mathrm{cc}$. of solution (1 to $1.5 \mathrm{mgm}$. of amidopyrine) being injected. (6) Following the principle of Horsfall (9) who worked with formaldehyde and who found that a combination of blood serum with the drug gave positive intradermal results, whereas solutions of formaldehyde in water gave negative readings, mixtures of 5 per cent amidopyrine solution with varying quantities of human blood serum were prepared and allowed to remain in the refrigerator for several days, after which intradermal tests were made on the above subjects, and on a number of normal controls. ${ }^{2}$ Control tests

2 The data obtained in the normal subjects together with other studies regarding possible allergic factors will be detailed in another report.

Of 34 normal controls (patients with normal leukocyte counts and without history of previous agranulocytosis), four showed striking reactions to the "serumized" amidopyrine solution. All of these individuals admitted having used amidopyrine on various occasions for relief of such complaints as headache, etc. One patient, when given amidopyrine 0.3 gram (10 grains) by mouth developed 
were made with a 5 per cent aqueous solution of amidopyrine and with the same blood serum kept in the refrigerator for an equivalent length of time.

\section{REPORTS OF CASES}

Case 1.3 Female, 49 years. Asthma and "sinusitis" for years; two relapses of agranulocytosis with recovery; amidopyrine in relapse 1; no drugs in relapse 2; third and fourth relapses initiated experimentally with amidopyrine.

Emily D. T., a housewife with a previous history of repeated attacks of tonsillitis, bronchitis, and asthma, and "sinus trouble," developed frontal sinusitis in November 1929 following an acute upper respiratory infection. Headache was quite severe, and she took a "great deal" of "pyramidon." In a period of about two weeks, she consumed "several" tubes containing ten 5 grain tablets of the drug. Two weeks after onset of sinusitis, she felt tired and weak, and soon developed severe sore throat and sores in the mouth. She continued to use pyramidon. Finally, she became desperately ill, almost moribund. Necrotic ulcerations were found in various parts of the buccal mucous membranes and throat. On December 24, the blood showed the following: white blood cell count 1,500 ; polymorphonuclears 1 per cent; lymphocytes 99 . Recovery occurred after a transfusion and the use of whole boiled milk intramuscularly.

Relapse II. The patient was well until May 1932, when she again developed one of her attacks of "sinusitis" following a "cold." She took much "aspirin" but no amidopyrine or other medication. Weakness, fever, and finally "sores" in the mouth and throat developed. She became prostrated and developed necrotic ulcerations of the throat and mucous membranes. She was found to have a leukocyte count of 2,400 with complete absence of granulocytes. Immediate treatment with pentnucleotide was instituted, and the patient made a satisfactory hematological, then clinical recovery.

Only one factor other than the drug amidopyrine appeared to be present in the first relapse, i.e. possible sinusitis. An allergic predisposition is suggested because of the repeated attacks of "bronchitis" and asthma in the past. Since amidopyrine was not taken in the second relapse, doubt may be cast on the importance of a drug as a factor, although it is possible that aspirin may have been of etiological significance.

severe malaise and nausea, generalized erythema, and on the following day, herpes labialis. Other studies are being done in this group of patients and in a group of children.

${ }^{3}$ This case has been previously reported in another paper (10).
The patient remained entirely well from April 1932 to August 1934. At several different times, leukocyte and differential counts were found normal. After a preliminary period of frequent observation in July and August 1934, during which leukocyte and differential counts were taken twice weekly, the patient took 0.6 gram (10 grains) of amidopyrine ("pyramidon") on August 16,1934 at 7 p.m. At 8:30 p.m. she developed severe headache, nausea, marked flushing of the face, malaise, vague pains in all the joints, and weakness. She slept poorly that night. On the following morning, August 17, she felt worse but again took amidopyrine in the same dosage (0.6 gram). She developed slight fever that day. On August 18, she felt very badly, and complained of severe headache similar to the " sinusitis" of previous attacks. On August 18, she fainted on arising from bed. Her mouth and throat were dry. Leukocyte count was 1,400 per c. mm. and only 2 per cent polymorphonuclear cells were present. On August 21, she felt extremely weak and continued to have intense headache. Leukocyte count was somewhat higher with more polymorphonuclear cells (Figure 1). On August 24, although the white blood cell count was 7,500, the granulocyte count was 1 per cent (!), and sores were noted on the tongue and the lips. On August 26, she had herpes and a red throat; again, although the leukocyte count was normal, she had only 1 per cent polymorphonuclear cells. On August 29, 14 per cent granulocytes were present. On September 11, she felt somewhat better and 25 per cent granulocytes were present. On September 26, the polymorphonuclear count was 50 per cent, and the patient felt almost as well as before administration of amidopyrine on August 16.

Scratch tests with a 5 per cent solution of amidopyrine were negative, as were patch tests.

Intradermal tests with a 5 per cent solution of amidopyrine in distilled water were negative, but tests made with the same solution of amidopyrine which had been mixed with blood serum for several days were strongly positive (Figure 2 ). The intradermal test with blood serum alone was negative.

These intradermal tests were made at 11 a.m. on February 18, 1935, after a period of five months of good health. Five tests were made: 


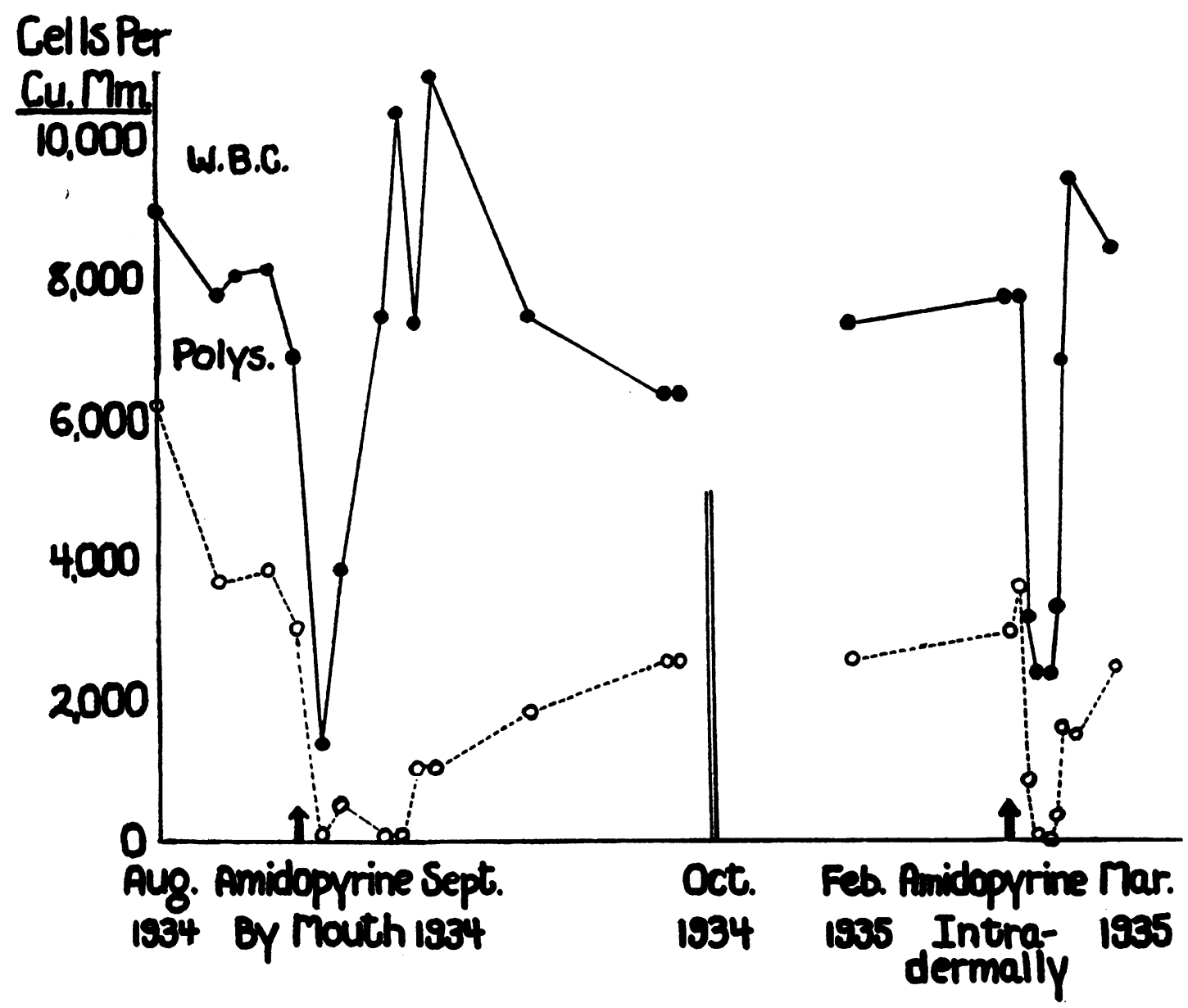

Fig. 1. The Effect of Administering Amidopyrine (1) Orally in 0.6 Gram (10 grains) Dosage and (2) Intradermally in About 10 mgm. (1/6 grain) Dosage on the Leukocyte and Granulocyte Counts of Patient Emily D. T.

Note the striking leukopenia and granulocytopenia produced in both instances.

one with blood serum, one with amidopyrine in 5 per cent solution, and three with "serumized" amidopyrine solution of various dilutions. The total quantity of amidopyrine injected did not exceed $10 \mathrm{mgm}$, (1/6 grain), and was probably more nearly $5 \mathrm{mgm}$. (1/12 grain). At 1:30 p.m. of the same day, $2 \frac{1}{2}$ hours after the tests, the patient developed headache which gradually became more and more intense. That night she was unable to sleep. The next morning (February 19) she was too weak to get out of bed and had excruciating headache. She was extremely weak, somewhat feverish, and nauseated. At 5:30 p.m., the patient was found lying in bed complaining of severe headache. Temperature was $100.2^{\circ} \mathrm{F}$, pulse 80 . Leukocyte count was 1,400 per c. mm., and differential count showed 28 per cent polymorphonuclear cells. On February 20, headache was intense, and the patient was prostrated. Temperature was $100^{\circ} \mathrm{F}$. The leukocyte count was now lower (Figure 1). On February 21, a cluster of small lesions, possibly herpetic, were present at the margins of the lips and the buccal mucous membranes. On February 22, many small superficial ulcerations were present on the buccal mucous membranes, and on the following day, a necrotic lesion was seen on the posterior pharynx. The headache continued to be very severe. On February 27, for the first time the patient was able to arise from bed, although headache was still intense. On March 1, headache continued, although the mouth lesions were healing. There 


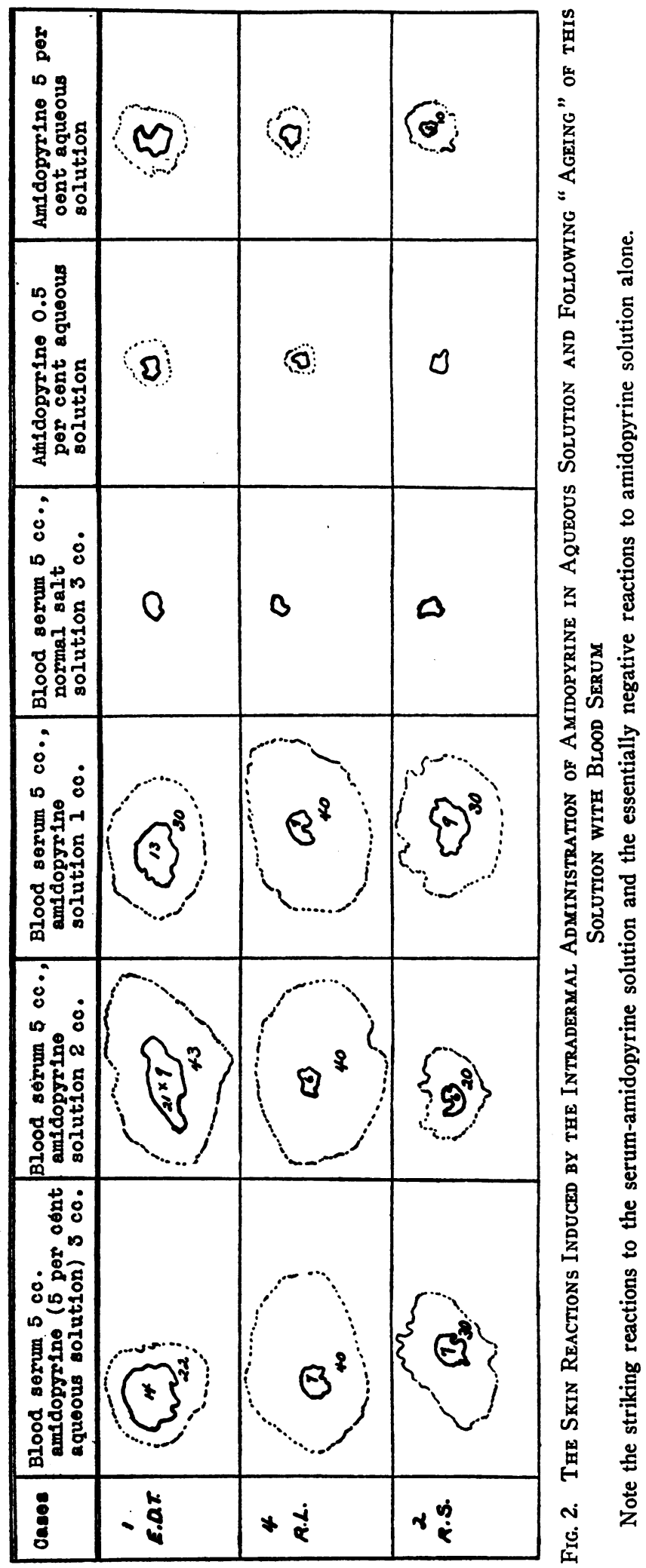




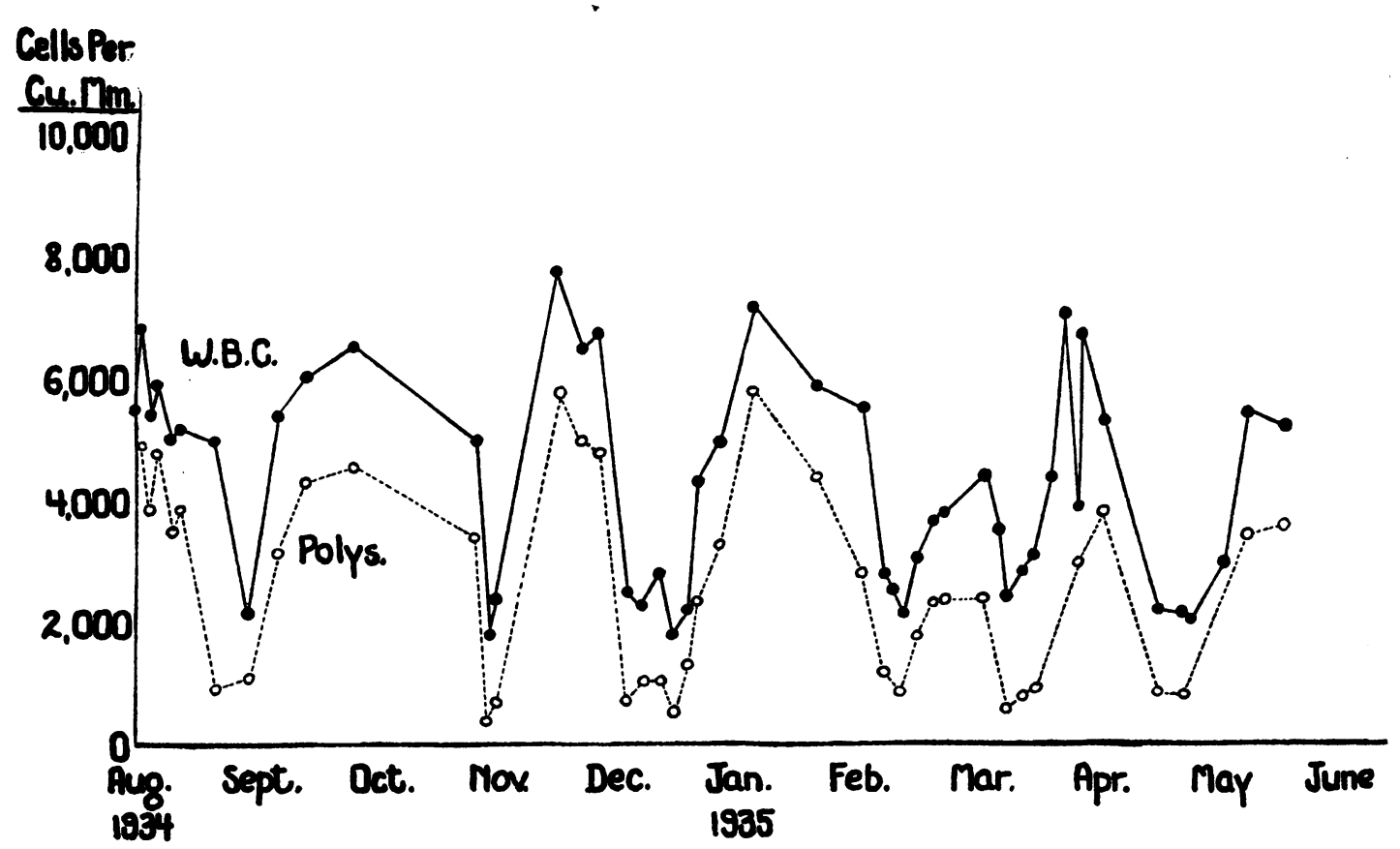

Fig. 3. The Spontaneous Changes in Total Leu kocyte and Granulocyte Counts in Patient R. S.

The irregular cyclical character of the leukopenia and granulocytopenia is evident.

was definite rise in the leukocyte count, although the polymorphonuclear count was still low. On March 8, the patient felt fairly well although slight headache and weakness were still present.

Case 2.4 B.I.H. 11,575, female, 45 years. Many illnesses, migraine for many years; cyclical granulocytopenia; constant use of amidopyrine; many bouts of agranulocytosis associated with various types of infection; treatment with nucleic acid derivatives; questionable experimental result with use of large dosage of amidopyrine.

Rose S., a single clerk, had always been " high-strung" and subject to frequent attacks of "indigestion" and migraine. In the past 8 or 10 years, she had used "aspirin" 10 grains and "pyramidon" 5 grains frequently for her attacks of migraine, which were present usually at weekly or more frequent intervals. This combination of medications was often repeated several times daily. In 1920 and 1929, she had pneumonia. In 1925 hysterectomy and oophorectomy were performed for fibroid uterus. In July 1931, December 1931, February 1932, and September 1933, she developed severe bouts of agranulocytosis associated respectively with pneumonia, necrotic ulceration of the tongue, depression, and an infection of a toe. Leukocyte count during the attacks varied between 800 and 2,400 per c. mm. with complete absence of granulocytes. The amount of amidopyrine

4 This case is reported fully in a previous paper (10). taken prior to these attacks could not definitely be determined since she took this medication (together with aspirin) frequently for migraine. All her attacks appeared to respond well to nucleic acid derivatives. Careful study after the attacks had subsided indicated a cyclical leukopenia, which occurred every 5 to 8 weeks (Figure 3 ) even when all drugs were discontinued.

Migraine, previous hysterectomy and oophorectomy, cyclical granulocytopenia at 4 to 8 week intervals, much use of amidopyrine and aspirin, infections of various types-all these factors probably contributed to the development of the numerous bouts of agranulocytosis. It was noted on several occasions that an infection or a traumatic lesion such as a cut finger occurring when the leukocyte count was normal failed to result in a bout of the disease. Mild agranulocytosis is frequently present in this patient and is associated with such mild symptoms as lassitude and depression. Clinical agranulocytosis probably does not develop in this case unless there is (1) marked leukopenia (cyclical) together with (2) the use of amidopyrine plus (3) the development of some such condition as a sore throat, "grippe," or a cut toe. These three factors together probably result in the fulminating disease. 
On April 8, 1934, this patient entered the hospital for study of the effect of amidopyrine on the leukocyte count. Hourly counts of the white cells and granulocytes were made on three successive days; on the first day no medication was given; on the second day amidopyrine, grains 10 (0.6 gram) was given every two hours for five doses (total 50 grains); on the third day again no medication was given. No essential change in white blood cells occurred during this period of observation. The patient was discharged home on April 10. Approximately two weeks later, she began to feel weak and feverish. On April 29, numerous lesions appeared on the lips, and the patient was prostrated. She again entered the hospital on April 30 with a temperature of $103^{\circ} \mathrm{F}$. Several herpetic lesions were present on both lips, which were moderately swollen. The remainder of the examination was negative. The leukocyte count was 2,000 to 2,900 per c. mm. with 50 per cent of polymorphonuclear cells. On the second day of admission, the patient's temperature was $100^{\circ}$, on the third day, $99.5^{\circ}$. The herpetic lesions of the lips gradually cleared. No definite change in the leukocyte count occurred. She was discharged on May 4, 1934 feeling much improved.

On October 29, 1934, scratch and patch tests with amidopyrine were made with negative results. On February 23, intradermal tests with amidopyrine in aqueous solution, and in mixtures with blood serum were made. The results of the tests are shown graphically in Figure 2, and demonstrate that the tests with "serumized" amidopyrine were strongly positive, although those with amidopyrine alone were negative. The patient developed neither constitutional nor definite hematological effects following these intradermal tests.

Case 3. B.I.H. 20,812, female, 27 years. Severe theumatic heart disease; hemithyroidectomy; rheumatic fever; administration of amidopyrine; granulocytopenia ; recovery following treatment with adenine sulphate; relapse initiated by amidopyrine.

Helen $\mathrm{K}$., a housewife, had had several attacks of rheumatic fever as a child, and had suffered from severe valvular heart disease. She had had several bouts of cardiac decompensation, and was also subject to attacks of severe anginal pain. On January 16, 1934, complete hemithyroidectomy was performed as a therapeutic procedure. Early in March 1934, she began to have rheu- matic pains and slight fever. Leukocyte count at this time was 5,700 to 6,000 per c. $\mathrm{mm}$., with 76 per cent polymorphonuclear cells. On March 7 and March 9 she was given amidopyrine 40 grains daily; on March 9 after a dose of 10 grains, the drug was omitted because of nausea. On March 12, leukocyte count was 5,500. On March 14 and 15 she was again given amidopyrine in daily dosage of 40 grains; the drug was omitted on March 16, when leukopenia was discovered. On March 15 the white blood cell count was 3,450; on March 16 it was 2,700; on March 22, 1,800 with 7 per cent polymorphonuclear cells. At this point adenine sulphate was administered in dosage of $1.0 \mathrm{gram}$ intravenously. The following day the temperature was higher, leukocyte count was 1,000 and there was sore throat, a few tender cervical lymph nodes, and a papulopustular eruption of the skin. On March 27, there was clinical improvement and the leukocyte count was 2,450 with 15 per cent polymorphonuclear cells. On April 5, 6, and 7, leukocyte count was about 8,000 and the granulocytes rose to 50 to 75 per cent.

Rheumatic fever, rheumatic heart disease, hemithyroidectomy, massive doses of amidopyrine. Of these factors, the last seemed most important since there was no disturbance in leukocyte count until after continued use of the drug.

When the leukocyte count had remained at a normal level $(8,000$ per c. $\mathrm{mm}$.) for three days, she was given amidopyrine in doses of 0.6 gram (10 grains) every three hours. Shortly after administration of the third (and last) dose, she complained of headache, nausea, epigastric distress, and she vomited. On the following morning, marked swelling of the lips (angioneurotic edema) was present. Leukocyte count was 4,300 per c. mm. with 63 per cent polymorphonuclear cells. On the following day it was 6,400 ; two days later, 5,400; three days later, 6,900 per c. $\mathrm{mm}$. Scratch and patch tests with amidopyrine as well as passive transfer (Prausnitz-Küster) tests were negative. The patient was shortly discharged from the hospital and further testing seemed undesirable.

Case 4. B.I.H. 22,060, female, 43 years. Infection about the anus; administration of amidopyrine and "allonal "; agranulocytosis; recovery following use of adenine sulphate.

Ruth L., a housewife, complained of pain about the anus and developed fever two months before admission to the hospital. An abscess of the anal region was discovered and drained. Later, hemorrhoidectomy was performed. She continued to have pain and a burning sensation about the anus, for which she took allonal and 
amidopyrine in small doses. In the week before admission to the hospital she took 10 "pyramidon" tablets and 6 tablets of allonal. She developed fever, sore mouth, nausea, and headache. Examination disclosed a temperature of $103^{\circ} \mathrm{F}$., herpetic lesions about the mouth, gingivitis, a small punched-out area at the tip of the tongue, and tenderness in the anal region. Routine blood findings on admission April 14, 1934 showed the following: hemoglobin 85 per cent; red blood cell count 4.45 ; white blood cell count 1,800; polymorphonuclear cells 8 per cent; lymphocytes 70 per cent; monocytes 2 per cent. On April 15, leukocyte count was 1,225; on April 16, the white blood cell count was 400 with complete absence of granulocytes. On April 15, she was given adenine sulphate in dosage of 1.0 gram intravenously; this was repeated for five doses. On April 17, leukocyte count was 700 with 3 per cent polymorphonuclear cells. On April 18, 60 hours after the first administration of the drug, the white blood cell count was 1,500 with 24 per cent granulocytes, most of which were myelocytes and metamyelocytes. From that time on, rapid clinical and hematological improvement took place. On April 23, leukocyte count was 19,800 with 49 per cent granulocytes. Subsequently, the leukocyte count came to normal, and the patient was clinically well.

The patient was observed at intervals for several months and was always found to have a normal blood picture. The leukocyte count varied between 7,000 and 8,600 per c. $\mathrm{mm}$. and the polymorphonuclear cells between 53 and 63 per cent.

On September 8, 1934, after a period of two weeks of frequent observations, scratch and patch tests with amidopyrine were performed. On the following day, the area of skin below the surface of the amidopyrine patch was light pink, the central portion being raised and whitish. On September 10 , the raised central portion was more prominent. On the 11 th there was definite fading but on the 15 th, seven days after the patch test was performed, the area of the test was purplish red and surrounded by a slight white halo. The leukocyte count on this day was 5,650 with 45 per cent polymorphonuclears, many of them very mature forms. On September 15, she was given amidopyrine grains 5 ( 0.3 gram) by mouth without any appreciable effect either generally or on the leukocyte count. On September 17 , the white cell count was 6,100 and on September 18, 6,200 with 58 per cent polymorphonuclear cells.

Except for sensations of weakness from time to time and aching in various joints, the patient was well for the next several months. Occasional leukocyte counts gave normal figures. On February 25,1935 , intradermal tests with solutions of amidopyrine in distilled water and in blood serum were done. The reactions to the amidopyrine solution in water were negative, but strikingly positive reactions to the amidopyrine-serum mixtures occurred (Figure 2). About $10 \mathrm{mgm}$. of amidopyrine had been injected. The patient was asked to return on March 1 for further testing. At this time, intradermal tests were done with the blood serum control and with a 5 per cent aqueous amidopyrine solution (containing about $1 \mathrm{mgm}$. of amidopyrine). The leukocyte count on February 25 was 6,400 per c. mm. with 63 per cent polymorphonuclears. On March 1, the date of further testing, the leukocyte count was 4,500 with 55 per cent polymorphonuclears.

On March 2, the patient complained of pain in the lower right quadrant of the abdomen; a physician who saw her found no elevation of temperature and no abnormal physical signs. On March 6 , she took to bed feeling weak and feverish and complaining of sore throat and sore gums; the abdominal pain had ceased. Temperature was $100^{\circ} \mathrm{F}$. On March 8, in addition to these symptoms, there was photophobia, pains in the region of the right ear, and extremely sore throat and gums. Examination disclosed dulling of the sensorium, ridges of raised, dry, necrotic-looking material on either side of the buccal mucous membranes, "dry" appearing gums with beginning areas of necrosis, marked dusky redness of the entire fauces, and large lymph nodes at the angles of the jaws. The leukocyte count was 4,200 per c. mm. Differential count showed only 1 per cent of mature polymorphonuclear cells; 2 metamyelocytes and 5 myelocytes were present. The lymphocytes numbered 60 per cent, the monocytes 32 per cent. On March 9, the symptoms of weakness, headache, pain in the right neck were still present, and in addition there was nausea. The leukocyte count was substantially the same (Figure 4). The necrotic areas of the buccal mucous membranes and gums gradually healed, and there was a gradual increase in the number of granulocytes. On March 17, weakness and slight headache were still severe; but the temperature was normal, and there were no abnormal physical signs. On March 22, the patient felt better al- 


\section{Cellsper \\ $\frac{\text { Cu. Mm. }}{10,000}$}

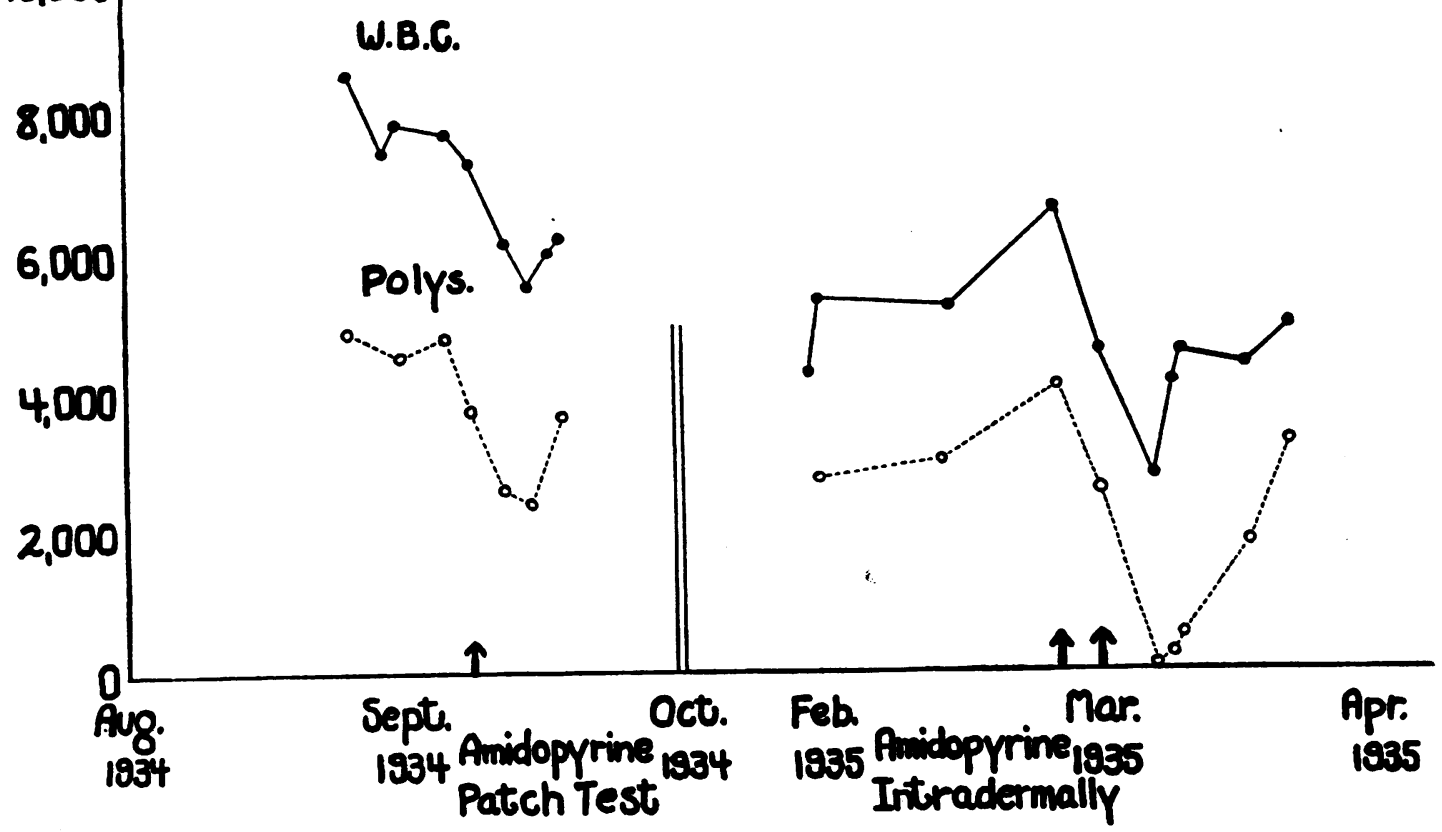

Fig. 4. The Effect on the Leukocyte and Granulocyte Counts in Patient R. L. of (1) a Patch Test with Amidopyrine and (2) Intradermal Tests with Amidopyrine and Control Solutions

The total amount of amidopyrine present in the testing solutions was about $10 \mathrm{mgm}$. (1/6 grain).

though still somewhat weak. Leukocyte count was 5,000 and 66 per. cent polymorphonuclear cells were present.

\section{DISCUSSION \\ Analysis of results}

The results obtained in the four cases selected for special study are recorded in Table II. It is seen that in three of the four cases $(1,2$, and 3 ) a reaction occurred following oral administration of amidopyrine. In Case 2 this reaction was delayed and therefore not conclusive. In Case 1 severe constitutional symptoms characterized by headache, nausea, vague generalized pains, etc. occurred within 90 minutes after ingestion of the drug. In two and a half days there was almost complete agranulocytosis. In Case 3 constitutional symptoms of headache, nausea, and epigastric distress appeared about six hours after the first administration of the drug. There was halving of the leukocyte count in 12 hours. Case 4 failed to react definitely to 5 grains of amidopyrine given orally, although a definite but slight leukopenia occurred. It is, to be sure, possible that the amount of drug given was too small to produce definite effect, for a severe reaction occurred later following intradermal tests.

The scratch and patch tests were uniformly negative, although in Case 4 there was a delayed reaction to the patch test which occurred in 4 or 5 days. Tests in which an attempt was made to use the rabbit as a reactor in a modified passive transfer reaction were inconclusive although first results proved suggestive.

Intradermal tests using an aqueous solution (5 per cent) of amidopyrine were entirely negative, but when the solution of amidopyrine was allowed to remain in contact with blood serum for several days and intradermal tests again performed, the results were striking. Marked local reactions occurred in all three patients tested with the serumamidopyrine mixtures. In a large series of normal subjects, only a few reacted to the serumamidopyrine mixtures. Striking general and 
TABLE II

Summary of the reactions induced by the administration of amidopyrine to a group of 4 patients who had recovered from agranulocytosis

\begin{tabular}{|c|c|c|c|c|c|c|c|c|c|}
\hline \multirow{3}{*}{$\begin{array}{c}\text { Case } \\
\text { number }\end{array}$} & \multirow{3}{*}{ Oral administration } & \multirow{3}{*}{$\begin{array}{c}\text { Scratch } \\
\text { test }\end{array}$} & \multirow{3}{*}{$\underset{\text { test }}{\text { Patch }}$} & \multicolumn{5}{|c|}{ Intradermal tests-local reaction } & \multirow{3}{*}{ Effect of intradermal tests on W.B.C } \\
\hline & & & & \multicolumn{2}{|c|}{$\begin{array}{l}\text { Amidopyrine } \\
\text { (aqueous } \\
\text { solution) }\end{array}$} & \multicolumn{3}{|c|}{$\begin{array}{l}\text { Amidopyrine ( } 5 \text { per cent } \\
\text { solution)-blood serum } \\
\text { mixtures }\end{array}$} & \\
\hline & & & & $\begin{array}{c}5 \\
\text { per cent }\end{array}$ & $\begin{array}{c}0.5 \\
\text { per cent }\end{array}$ & $3-5$ & $2-5$ & $1-5$ & \\
\hline 1 & $\begin{array}{l}(1.2 \text { gram }) \\
\text { W.B.C. } 1400 \\
\text { Polys. } 2 \text { per cent }\end{array}$ & 0 & 0 & 0 & 0 & +++ & +++ & +++ & W.B.C. 2200. Polys. 0 \\
\hline 2 & $\begin{array}{l}(3.0 \text { gram }) \\
\text { W.B.C. } 2000 \\
\text { Polys. } 50 \text { per cent }\end{array}$ & 0 & 0 & $\mathbf{0}$ & 0 & +++ & ++ & ++ & No definite reaction \\
\hline 3 & $\begin{array}{l}(1.8 \text { gram }) \\
\text { W.B.C. } 4300 \\
\text { Polys. } 63 \text { per cent }\end{array}$ & 0 & 0 & & & & & & \\
\hline 4 & $\begin{array}{l}\text { (0.3 gram) } \\
\text { No effect }\end{array}$ & 0 & + & 0 & 0 & +++ & +++ & +++ & W.B.C. 2750. Polys. 0 \\
\hline
\end{tabular}

dermatological reactions have occurred in the first two positively reacting subjects following the oral administration of amidopyrine. This part of the work is still in progress. In two of the cases of agranulocytosis, as noted above, the entire clinical and hematological picture was unexpectedly reproduced following these intradermal tests. Case 1 reacted in striking fashion to both the oral and intradermal administration of the drug, about 10 mgm. given intradermally creating as much disturbance as 10 grains ( 0.6 gram) given orally. Case 4 is more instructive in this respect since 5 grains ( 0.3 gram) given orally failed to produce a definite reaction, although about $10 \mathrm{mgm}$. given intradermally produced a striking hematological and clinical effect. This suggests a definite gastrointestinal "barrier" to the extent of at least 30 times. The fact that intradermal tests with an aqueous solution of amidopyrine were negative whereas similar tests with the same solution "aged" in blood serum were strongly positive suggests a drug-protein linkage in the hypersensitivity to amidopyrine. This is in line with the observations of Landsteiner and Van Der Scheer (11) who demonstrated that linkage of single chemicals to protein molecules gave rise to new antigenic substances whose specificity was determined by the non-protein portion of the resultant compound.
The theory of hypersensitivity to various drugs

Understanding of the etiology of agranulocytosis was greatly advanced by the publications of Kracke and Parker (12) and of Madison and Squier (2). Emphasis formerly placed upon infections, hypothetical toxins, an inherent leukopenic tendency, the menstrual cycle, etc. became completely shifted to certain chemicals which were commonly used as therapeutic agents. The mechanism by which these drugs brought about an extreme reduction in granulocytes could only be inferred since animal experimentation was for the most part unsatisfactory. Most authors suggested that certain patients were hypersensitive to the various drugs which had been incriminated. Kracke and Parker (12), however, postulated a direct chemical action upon the bone marrow through the medium of certain oxidation products of the "benzamine" drugs.

It was obvious that if amidopyrine and certain other drugs were the chief causes of agranulocytosis, some other factor must be present as well since so few cases of agranulocytosis occurred among the many users of the drugs. Numerous observers therefore suggested the factor of individual idiosyncrasy, hypersensitivity, or " allergy." That certain individuals are unusually sensitive to certain drugs (arsphenamine, potassium iodide, cinchophen, etc.) is well known. This hyper- 
sensitivity has been previously associated with such organs as the skin and the liver; the bone marrow has heretofore not been implicated.

Pepper (13) some years previously had suggested that agranulocytosis might be on an "allergic" basis; this suggestion was based simply on the fact that certain patients with the disease had a background or family history of allergy. Madison and Squier. (2) emphasized the possibility of hypersensitivity to amidopyrine, and Watkins (14) stated that there was a definite possibility of idiosyncrasy to the drug, which together with a "primary dysfunction of the bone marrow" resulted in the disease. Hoffman, Butt, and Hickey (15) suggested that the disease might be on the basis of individual susceptibility in the nature of an allergic reaction. Groen and Gelderman (16) thought that idiosyncrasy to certain drugs might be inherent in certain individuals, and pointed to the case of deVries in which "a few hundred milligrams of pyramidon" regularly caused chill and granulocytopenia. Reznikoff (3) stated that "it is obvious that one is dealing with a question of sensitivity in certain patients rather than with a universal action of the drug."

A recent survey ${ }^{5}$ indicates that about 30 million prescriptions for the numerous preparations containing amidopyrine are filled annually. This figure does not take into account the large amounts used in hospitals and other institutions or sold directly over the drugstore counter. Less than 500 cases of agranulocytosis have been reported in the United States in the past five years. If it is assumed that ten times as many cases were present as were reported, then about 5,000 cases of the disease might possibly have been present. This is obviously an exaggerated figure, but even utilizing this figure only one case of agranulocytosis develops as the result of approximately 6,000 prescriptions containing amidopyrine. If hospital and over-the-counter usage are considered, the case incidence becomes even smaller, possibly 1 case in 10,000 prescriptions. This figure alone suggests that striking hypersensitivity to the drug is probably present before the disease agranulocytosis develops.

Benjamin and Biederman (5) attempted to de-

\footnotetext{
5 These figures were kindly supplied to us by the Research Division of the Winthrop Chemical Co.
}

fine more accurately the nature of this hypersensitivity. Since patch tests, intracutaneous tests, and passive transfer tests in their patient reacting to the oral administration of amidopyrine were all negative, these authors concluded that the reaction was " not atopic" but "more in the nature of a drug hypersensitivity with the hematopoietic system acting as a shock organ."

Certain individuals appear to have an unusually marked sensitivity to amidopyrine resulting in (a) constitutional symptoms (fever, prostration, headache), (b) dermatological manifestations (herpes labialis, angioneurotic edema), and (c) leukopenia. The latter is presumably due to a direct action on the bone marrow, more particularly on the leukopoietic portion of the marrow. The exact nature of this action on the marrow is not at present understood. Fitz-Hugh and Krumbhaar (17) postulated a "maturation arrest" in the disease, with failure of the myeloblastic cells of the bone marrow to maturate beyond a given point. One of us (W. D.) in a series of unpublished experiments has recently been able to induce leukopenia in normal individuals by the continued administration of drugs containing amidopyrine. When these drugs were discontinued, most cases showed pronounced leukocytosis (" release phenomenon") suggesting either that the drug had induced an inhibition of cellular maturation or of delivery of leukocytes from the bone marrow to the blood stream. It is therefore possible that certain individuals with an altered reactivity (" allergy," hypersensitivity) are profoundly affected by minute doses of such drugs as amidopyrine with resultant effect either on cellular maturation in the bone marrow or upon the delivery mechanism from the marrow to the circulating blood.

\section{The theory of direct action of the drug or its oxidation products upon the bone marrow}

Kracke and Parker (12) have been the chief protagonists of the theory that agranulocytosis is due to a direct toxic effect of various drugs or their oxidation products upon the marrow. They list gold salts, arsphenamine, amidopyrine, and phenacetin as containing easily oxidizable benzene rings, and suggest that oxidation products such as catechol and quinon probably affect the marrow directly to produce the disease. They also sug- 
gest that this oxidation takes place in the gastrointestinal tract. They state, "It is logical to assume that rabbits as well as human beings have an adequate protective mechanism against the action of drugs of this class. . . . It can be readily seen that the injection of these drugs, whether it be subcutaneous, intraperitoneal or intravenous, would result in little opportunity for oxidation to the more toxic products, whereas the oral administration of the same drugs would ... . lend them to easy oxidation in the gastro-intestinal tract." The evidence given for these statements appears to be inadequate and often speculative. It has, furthermore, been demonstrated from our two cases in which agranulocytosis followed the intradermal injection of small quantities of amidopyrine that injection of the drug may produce the disease and that "oxidation" by the gastro-intestinal tract is not a requisite.

That only certain individuals should develop agranulocytosis with the same drug presupposes, according to the theory of Kracke and Parker, either excessive dosage or a defective marrow. Judging from our cases, excessive dosage is probably not as important a fact as unusual sensitivity to the ordinary dosage. That a defective marrow may, however, be of importance is possibly demonstrated in our cases of pernicious anemia and hypoplastic anemia which developed agranulocytosis. It is, to be sure, possible that all of these conditions, i.e. hypersensitivity, excessive dosage, and a defective marrow must be operative in a given case before agranulocytosis develops. Multiple etiological factors, while essential for the development of certain cases, are doubtless not as important as the factor of hypersensitivity to a drug, usually amidopyrine. This factor appears to be present in the great majority of cases of the disease. Whether this "allergic" state is congenitally present or acquired during life will be the subject of further investigation. There can be no doubt, however, from these studies that certain individuals who are unusually sensitive to amidopyrine develop a bone marrow reaction which results clinically in agranulocytosis.

\section{SUMMARY AND CONCLUSIONS}

1. In twelve cases of agranulocytosis, although many etiological factors seemed operative, the only constant one was that of a drug, usually amido- pyrine, administered either alone or in combination. Of eight recovered cases, four were selected for special study of possible hypersensitivity to drugs.

2. The subjects were tested with amidopyrine which was given orally, by scratch test, patch test, passive transfer test, and intradermal test. Finally, intradermal tests were performed with a mixture of an aqueous solution of amidopyrine and blood serum.

3. One patient reacted strikingly (within 90 minutes) to the oral administration of 0.6 gram (10 grains) of amidopyrine with the resultant clinical and hematological manifestations of agranulocytosis. Two other patients developed moderate leukopenic and clinical reactions; the fourth patient, given 0.3 gram ( 5 grains) of the drug, developed no symptoms. The skin reactions to various scratch tests, patch tests, passive transfer tests, and intradermal tests with the drug alone were essentially negative. However, intradermal tests with a mixture of the drug and blood serum were strongly positive in all three cases tried.

4. Two of three patients, shortly after the intradermal administration of amidopyrine solutions for skin testing, developed all of the clinical and hematological features of agranulocytosis. The total quantity of amidopyrine used in these tests did not exceed $10 \mathrm{mgm}$. (1/6 grain).

5. Numerous reports demonstrate that the use of drugs, particularly of amidopyrine both alone and in combination is an important cause of agranulocytosis. The widespread use of these drugs and the relatively few cases of the disease suggest an idiosyncrasy or hypersensitivity on the part of certain individuals.

6. Our experimental observations present conclusive evidence of extreme hypersensitivity on the part of certain individuals to amidopyrine. The production of agranulocytosis following the intradermal introduction of only a few milligrams of the drug tends to disprove the theory that the drug must be oxidized in the gastro-intestinal tract before it can become toxic.

7. The negative intradermal tests with an aqueous solution of amidopyrine as contrasted with the strongly positive tests with a "serumized" solution suggest a possible drug-protein linkage as the basis of the "allergic" or hypersensitive reaction. 
8. The fundamental mechanism by which the bone marrow becomes affected and agranulocytosis results has not yet been demonstrated. These observations together with others suggest that certain drugs may cause suppression (" maturation arrest") of granulocyte production. In an individual who is hypersensitive ("allergic") to a given drug, a minute amount may initiate the disease.

\section{BIBLIOGRAPHY}

1. KRACKE, R. R., Recurrent agranulocytosis. Report of an unusual case. Am. J. Clin. Path., 1931, 1, 385.

2. Madison, F. W., and Seuier, T. L., The etiology of primary granulocytopenia (agranulocytic angina). J. A. M. A., 1934, 102, 755.

3. REZnIKofF, PAUL, The relation of amidopyrine and the barbituric acid derivatives to granulocytopenia. J. A. M. A., 1934, 102, 2183.

4. Jackson, Henry, JR., and Parker, Frederic, JR., Agranulocytosis. Its etiology and treatment. New England J. Med., 1935, 212, 137.

5. Benjamin, J. E., and Biederman, J. B., Agranulocytic leukopenia. J. A. M. A., 1934, 103, 161.

6. Sturgis, C. C., and IsaAcs, Raphael, Observations concerning the etiology of agranulocytosis. Tr. A. Am. Physicians, 1934, 49, 328.

7. Rawls, W. B., Neutropenia developing during amidopyrin medication, with report of two cases. Am. J. M. Sc., 1934, 187, 837.
8. Zinberg, I. S., Katzenstein, L., and Wice, L. E., Neutropenia following the administration of amidopyrine. Report of a case. J. A. M. A., 1934, 102, 2098.

9. Horsfall, F. L., JR., Formaldehyde serum proteins. Their immunological characteristics. Am. J. Immunol., 1934, 27, 553.

10. Dameshek, W., Agranulocytosis. Report of three cases treated with nucleic acid derivatives. New England J. Med., 1933, 209, 1054.

11. Landsteiner, K., and Van der Scheer, J., Anaphylactic shock by azo dyes. J. Exper. Med., 1933, $57,633$.

12. Kracke, R. R., and Parker, F. P., The etiology of granulopenia (agranulocytosis) with particular reference to drugs containing the benzene ring. Am. J. Clin. Path., 1934, 4, 453.

13. PEPPER, O. H. P., Leukopenia-A review; with special reference to agranulocytic angina. California and West. Med., 1931, 35, 82.

14. Watkins, C. H., The possible role of barbiturates and amidopyrine in causation of leukopenic states. Proc. Staff Meet. Mayo Clin., 1933, 8, 713.

15. Hofrman, A. M., Butt, E. M., ANd Hickey, N. G., Neutropenia following amidopyrine. Preliminary report. J. A. M. A., 1934, 102, 1213.

16. Groen, J., and Gelderman, C. J., Úber Agranulocytose (maligne neutropenie) durch Medikamente. Folia haematol., 1934, 52, 430.

17. Fitz-hugh, T., JR., and KrUmbhaAR, E. B., Myeloid cell hyperplasia of the bone marrow in agraulocytic angina. Am. J. M. Sc., 1932, 183, 104. 